\title{
Saúde e segurança no ambiente rural: uma análise das condições de trabalho em um setor de ordenha
}

\author{
Health and safety at rural environment: an analysis of work conditions in a milking sector
}

\author{
Leonardo Rocha MaiaI Luciano Brito Rodrigues ${ }^{\text {II }}$
}

\section{RESUMO}

A saúde e a segurança no trabalho são fatores preponderantes em todos os setores produtivos, assim como no agronegócio e, especificamente, na cadeia produtiva do leite. Neste artigo, apresentam-se os resultados de uma análise das condições do ambiente de trabalho de um setor de ordenha de leite localizado na região Sudoeste do Estado da Bahia. Buscouse identificar os riscos ocupacionais (físicos, químicos, biológicos, ergonômicos e de acidentes), bem como aspectos relativos à higiene do alimento. A pesquisa consistiu de um estudo de caso, com características qualitativas e exploratórias, tendo por finalidade descrever a situação encontrada no setor, confrontando-a com as legislações vigentes. Foram diagnosticados, predominantemente, riscos ergonômicos e de acidentes, além de irregularidades nas condições higiênicosanitárias, que podem constituir riscos biológicos. Não foram constatados riscos químicos ou físicos no setor. Os resultados apontam para a necessidade de melhoria no setor, que vão desde mudanças estruturais, questões organizacionais, como o oferecimento de treinamentos sobre procedimentos operacionais e em saúde e segurança no trabalho.

Palavras-chave: riscos ocupacionais, segurança no trabalho, ergonomia, ordenha.

\section{ABSTRACT}

The health and safety at work are important and might be considered as essential and relevant for all productive sectors, including agribusiness, specifically in the milk chain production. This paper presents the results of an environment work conditions analysis in a milking sector at southwest region of Bahia State. The study aimed to identify the occupational risks (physical, chemical, biological, ergonomic and accidents), as well as aspects related to food hygiene. The research consisted

\begin{abstract}
in a case study with qualitative and exploratory characteristics, aiming to observe and report the real conditions identified in the work environment and comparing with the current legislation. It was diagnosed predominantly ergonomic and accident risks, as well as irregular sanitary conditions that can result in biological risks. It was not found chemical or physical risks in the sector. Facing the results, it was proposed some recommendations involving issues related to organizational conditions, by offering training on operational procedures and health and safety at work.
\end{abstract}

Key words: occupational risks, occupational safety, ergonomics, milking.

\section{INTRODUÇÃO}

O agronegócio do leite representa uma das mais importantes atividades do setor rural. Encontra-se presente em grande parte das médias e pequenas propriedades, gerando renda nos estabelecimentos agropecuários, quer seja como atividade econômica principal, quer seja como atividade complementar ou suplementar nas propriedades agropecuárias (FAESP, 2010). OBrasil é o quinto maior produtor de leite do mundo, ficando atrás da União Européia, Estados Unidos, Índia e Rússia. Entre os estados, Minas Gerais lidera a produção nacional com cerca de $26 \%$, seguido pelo Rio Grande do Sul com 15,8\%. Os estados da Bahia e Pernambuco são os maiores produtores de leite da região Nordeste(IBGE, 2010).

IUniversidade Estadual do Sudoeste da Bahia (UESB), Itapetinga, BA, Brasil.

IIDepartamento de Tecnologia Rural e Animal, UESB, Campus de Itapetinga, Praça Primavera, 40, 45700-000, Itapetinga, BA, Brasil. E-mail: rodrigueslb@gmail.com. Autor para correspondência. 
Socialmente, o leite desempenha um relevante papel, principalmente na geração de empregos. Em 2001, o país tinha por volta de 1 milhão e 100 mil propriedades que exploravam leite, empregando diretamente 3,5 milhões de pessoas. Para exemplificar a importância deste setor na economia, a elevação na demanda final por produtos lácteos em 400 mil dólares geraria 195 empregos permanentes. Este impacto supera o de setores tradicionalmente importantes como o automobilístico, o da construção civil, o siderúrgico e o têxtil(VILELA, 2001).

Todavia, este desenvolvimento, e consequente oferta de empregos, traz consigo a preocupação com os acidentes de trabalho e doenças ocupacionais, que podem ocorrer em diversos ambientes e afetar qualquer trabalhador, trazendo para eles consequências como a interrupção temporária das atividades laborais e até a morte (RODRIGUES \& SANTANA, 2010). A Norma Regulamentadora 17, do Ministério do Trabalho e Emprego, que dispõe sobre Ergonomia estabelece, dentre outros tópicos, que as condições dos ambientes de trabalho devem estar adequadas às características psicofisiológicas dos trabalhadores e à natureza da atividade a ser executada, de modo a proporcionar um máximo de conforto, segurança e desempenho eficiente (BRASIL, 2007).

Segundo a Organização Internacional do Trabalho - OIT, o setor rural é uma das atividades de maior índice de acidentes no mundo, ao lado da construção civil e mineração. Os acidentes fatais giram em torno de 170 mil trabalhadores por ano na agroindústria mundial. Desde 1921, a OIT adota diversas convenções referentes a aspectos das atividades agrícolas, inclusive a segurança e saúde no desenvolvimento do trabalho (GALVÃO, 2011).

No Brasil, a Lei no 5.889 de 08 de junho de 1973, que regula o trabalho rural, traz em seu artigo $13^{\circ}$ que, nos locais de trabalho rural, deverão ser observadas as normas de segurança e higiene, estabelecidas em Portarias do Ministério do Trabalho e Previdência Social (BRASIL, 1973). Em 1988, estemesmo ministério, por meio da Portaria no 3.067 de 12 de abril, aprovou as cinco Normas Regulamentadoras Rurais, relativas à segurança e higiene do trabalho rural (BRASIL, 1988). Do mesmo modo como havia ocorrido para os demais setores que já dispunham de normas regulamentadoras próprias, os trabalhadores do campo passaram a ter uma legislação específica que contemplava as necessidades inerentes às suas atividades. Todavia, estas, ao longo dos anos de sua vigência, eram questionadas quanto ao seu conteúdo, apresentando limitações e não atendendo, segundo especialistas, as reais necessidades do trabalho rural (SOARES, 2007; GALVÃO, 2011). Assim, no ano de 2005, em substituição às Normas Regulamentadoras
Rurais (revogadas pela Portaria GM 191 de 15/04/2008), entrou em vigor a Norma Regulamentadora 31, que trata da Segurança e Saúde no Trabalho na Agricultura, Pecuária Silvicultura, Exploração Florestal e Aquicultura. Esta norma tem por objetivo estabelecer os preceitos a serem observados na organização e no ambiente de trabalho, de forma a tornar compatível o planejamento e o desenvolvimento das atividades nos setores por ela contemplados (BRASIL, 2005).

Isto mostra que as preocupações sobre as condições de segurança no trabalho rural são tanto recentes como de extrema relevância para o país, o que reforça a necessidade de estudos que permitam verificar em quais condições os trabalhadores rurais estão exercendo suas atividades, de modo que, diante de possíveis não conformidades, possam ser feitas sugestões e intervenções que contribuam para um melhor conforto, segurança e qualidade de vida desses profissionais.

Portanto, torna-se clara a necessidade de conhecer melhor as condições dos ambientes de trabalho do setor rural, mais especificamente neste trabalho, em um setor de ordenha de leite, visto que as atividades nele desenvolvidas demandam cuidados acentuados em relação ao controle de produtos, podendo acarretar desgastes emocionais, físicos e psicológicos ao trabalhador e influenciar diretamente no ritmo de produção (RODRIGUES et al., 2008). SILVA et al. (2011) destacam a escassez de informações sobre o bem-estar do trabalhador rural em sistemas de produção de bovinos, citando como problemas mais notados os de origem postural.

Este trabalho analisou as condições de higiene e segurança no trabalho presentes em um setor de ordenha de leite da região Sudoeste do Estado da Bahia. Para isso, buscou-se caracterizar o setor, verificando suas condições de funcionamento, sendo ainda identificados os riscos ocupacionais - físicos, químicos, biológicos, ergonômicos e de acidentes (ZOCCHIO, 2002) -, bem como aspectos relativos à higiene do alimento.

\section{MATERIAL E MÉTODOS}

O trabalho consistiu de um estudo de caso, com características qualitativas e exploratórias, tendo por finalidade descrever a situação encontrada no setor, confrontando-a com a legislação vigente. Quanto à abordagem, esta pesquisa teve características qualitativas, uma vez que foi baseada na opinião de pessoas relacionadas com o trabalho desenvolvido, sem a consideração de dados estatísticos.

A coleta de dados foi efetuada de duas maneiras, primeiramente, através de levantamentos exploratórios, de arquivos de base de dados e, posteriormente, por meio de levantamentos que foram feitos no próprio setor. Dentre os diversos tipos de instrumentos 
de coleta de dados existentes, foram utilizadas, para fins desta pesquisa, a entrevista não estruturada, aplicação de questionário e observação in loco. A entrevista não estruturada é aquela em que é deixado ao entrevistado decidir-se pela forma de construir a resposta. Seu uso é justificado, pelo fato de que muitos problemas e fenômenos das relações que permeiam o objeto de estudo escaparem ao pesquisador quando expressos em números e estatísticas (MATTOS, 2005). Com relação à técnica de observação, foi realizada a observação in loco, descrevendo tudo o que foi visualizado durante a visita ao local de trabalho. Em geral, as observações validam o resultado de outras técnicas e, por meio da confrontação dessas informações, que foram evidenciados os pontos críticos do setor (NEUENFELD et al., 2006).

A avaliação foi constituída de uma observação sistemática e entrevistas informais, em que se procurou observar as condições do local de trabalho: instalações físicas, condição de maquinários e atividades desenvolvidas pelo trabalhador. O estudo da organização dos postos de trabalho consistiu na determinação do processo produtivo: fluxo de entrada, procedimentos envolvidos, maquinário utilizado, mão de obra requerida, distribuição das atividades no espaço físico e fluxo de saída.

Foi aplicado um questionário, desenvolvido pela equipe executora do projeto, o qual era composto de 15 questões (10 qualitativas e 5 quantitativas), baseadas nas Normas Regulamentadoras 6, 9, 17, 24 e 31, do Ministério do Trabalho e Emprego e na Instrução Normativa 51 (IN 51), do Ministério da Agricultura Pecuária e Abastecimento. O questionário proposto abrangeu questões relacionadas à ergonomia, aspectos higiênicosanitários e uso de equipamentos de proteção individual.

\section{RESULTADOS E DISCUSSÃO}

A partir das observações, foram obtidos, como resultados da análise, a caracterização do setor, bem como a descrição das atividades nele desenvolvidas e ainda os riscos ocupacionais presentes. Neste caso, foram identificados os riscos ergonômicos, biológicos e mecânicos. A seguir, tais pontos serão discutidos separadamente.

\section{Caracterização do setor}

O setor corresponde a uma área de aproximadamente $165 \mathrm{~m}^{2}$, que é dividida em 3 sub-setores: bezerreiro, curral e sala de ordenha. Anexo ao setor existe um banheiro com vestiário de $30 \mathrm{~m}^{2}$. O modelo de ordenha adotado é definido como "Em Linha”, no qual os animais ficam paralelos ao fosso.

No período da coleta de dados, eram ordenhadas 19 vacas, com uma produção aproximada de 160 litros de leite/dia. Segundo informações colhidas junto aos funcionários do setor, este é o valor médio ao longo do ano. Com base nestes valores, percebe-se que, em relação ao número de vacas ordenhadas, a área do curral mostrou-se satisfatória, tendo, inclusive, condições de comportar mais animais. O fator limitante de produção é, nesse caso, a sala de ordenha onde só podem entrar o tamanho do curral e do bezerreiro, visto que, na sala de ordenha, só podem entrar seis animais simultaneamente. O curral mostra-se capaz de comportar aproximadamente 35 animais, o que é superior ao pico de ordenha do setor que são 24 vacas. Já o bezerreiro, capaz de comportar cerca de 10 animais, no período da coleta era ocupado por 5 animais.

\section{Descrição das atividades no setor}

Todas as tarefas são executadas por dois funcionários: A(57 anos) e B (38 anos) do sexo masculino e grau de escolaridade Fundamental (I) completo. O trabalho rural tem por característica a prevalência do sexo masculino na execução das atividades. FEHLBERG et al. (2001), em um estudo realizado na zona rural do município de Pelotas (RS), identificaram que dos 580 trabalhadores rurais entrevistados cerca de $60 \%$ eram do sexo masculino. Tal pesquisa, embora tenha sido feita em um município, reflete uma tendência nas atividades deste setor em todo o país.

A rotina do processo de ordenha inicia-se por volta das seis da manhã com o agrupamento das vacas em lactação no curral ao lado da área de ordenha. Posteriormente, é efetuada a limpeza dos galões que armazenarão o leite durante o processo de ordenha. Os animais são transferidos para a sala de ordenha em dois grupos, cada um contendo três animais. As matrizes leiteiras que possuem bezerros em período de amamentação são ordenhadas com a técnica de bezerro ao pé. Cada animal tem as patas traseiras amarradas (para facilitar a ordenha) e é feita a retirada dos dois primeiros jatos de leite na caneca de fundo preto, para checar se há sinal de mastite. Caso o resultado seja negativo, procedese à lavagem e secagem dos tetos, do contrário, o animal é identificado e solto no pasto para posterior tratamento. Para manter os tetos limpos e evitar a mastite, faz-se o pré-dipping (uma desinfecção do teto com solução sanitizante própria a essa finalidade, a base de cloro ou de iodo). Feito isso, as teteiras são colocadas e dá-se início à ordenha. Terminada a coleta, retiram-se as teteiras, que são imersas em água com sanitizante, e o animal passa pelo pós-dipping para que não ocorra contaminação pós-ordenha. Posteriormente, ocorre a soltura do animal no pasto. Essas ações são repetidas até que todas as vacas tenham sido ordenhadas. Ressalta-se que, para facilitar a ejeção do leite em algumas vacas, é feita a aproximação do bezerro à matriz leiteira e 
que, durante todo o processo de ordenha, há a preocupação de não causar estresse ou danos à integridade física dos animais, apesar de terem, por exemplo, as patas traseiras amarradas.

Finalizada a ordenha, os funcionários alimentam os bezerros - tarefa essa, exercida de forma manual com o auxílio de uma espécie de mamadeira adequada a estes animais. Findando a rotina, ambos os funcionários limpam a ordenhadeira mecânica (que é constituída de três etapas: enxágue inicial com água morna, limpeza com detergente alcalino e limpeza com detergente ácido), a sala de ordenha (uso de jato de água) e os currais (através do recolhimento do esterco).

Toda a rotina do processo de ordenha dura aproximadamente 3 horas, na qual cada animal permanece na sala de ordenha, por volta de 10 minutos.

\section{Riscos ergonômicos}

Durante a jornada de trabalho, todas as atividades são realizadas em pé, atingindo diretamente os membros inferiores, os quais suportam de 33 a $40 \%$ do peso do corpo humano. A manutenção desta postura por longos períodos podem causar, dentre outros problemas, dores e varizes (IIDA, 2005). Para SALIBA (2008), o tempo de manutenção de uma postura deve ser o mais breve possível, pois seus efeitos, eventualmente nocivos, dependem do tempo durante o qual ela será mantida. Contudo, o mesmo autor salienta que a escolha da postura em pé está justificada nos casos em que a tarefa exija operações frequentes em vários locais de trabalho, fisicamente separados.

A Norma Regulamentadora 17 estabelece que, para as atividades em que os trabalhos sejam realizados de pé, devem ser colocados assentos para descanso em locais que possam ser utilizados por todos os trabalhadores durante as pausas (BRASIL, 2007). Do mesmo modo, a Norma Regulamentadora 31 preconiza que, para as atividades que forem realizadas necessariamente em pé, devem ser garantidas pausas para descanso (BRASIL, 2005).

O trabalho no setor exige esforço físico moderado com levantamento e transporte manual de pesos (sem auxílio de equipamentos de transporte auxiliar), tornando o trabalho um processo mecanicamente estressante e envolvendo um alto custo energético, devido à tensão mecânica contínua exercida sobre os músculos dos braços e das costas durante o transporte dos pesos (DUL \&WEERDMEESTER, 2004). Por exemplo, em etapas como a imobilização das patas traseiras, levantamento dos galões com leite, aproximação entre a vaca e a cria foram observadas inclinações errôneas do tronco e movimentos moderados e repetitivos dos braços. Estas situações podem provocar fadiga, dores corporais, dentre outros, os quais podem acarretar afastamento do trabalho por doenças ocupacionais, como a lombalgia, que é uma das principais causa de absenteísmo (ALEXANDRE, 1998; DUL \& WEERDMEESTER, 2004). BEZERRA etal.(1998)mostram que trabalhadores que utilizavam postura incorreta, costas curvadas, sobretudo devido ao fato de, segundo eles, não terem recebido nenhuma orientação de qual seria a melhor posição de se executar a tarefa, apresentaram como principal problema a lombalgia. Em virtude disso, a Norma Regulamentadora 31 designa que o trabalhador responsável pelo transporte manual regular de cargas deve receber treinamento ou instruções quanto aos métodos de trabalho que deverá utilizar, com vistas a salvaguardar sua saúde e prevenir acidentes (BRASIL, 2005).

Tais observações confirmam o descrito por REINEMANN (2005), que considera a ordenha uma tarefa que tem um alto risco de lesão por esforço repetitivo, visto que os trabalhadores ficam em posturas e movimentos de funcionamento que envolve andar, sentarse, levantar-se, ajoelhar-se, inclinar-se, dobrar-se, torcerse e esticar-se, sendo esta a situação de funcionamento usual para a maioria de produtores e de trabalhadores de fazenda na produção leiteria.

\section{Riscos biológicos}

De forma geral, as atividades são realizadas considerando os aspectos de higiene e segurança do alimento. Como já descrito anteriormente, o processo de ordenha é feito de forma mecânica, com a mínima interação entre o operador e o produto, por isso não foram encontrados problemas graves no setor avaliado, apenas alguns descuidos.

Primeiramente, na área de ordenha, foi observada remoção indevida do lixo, ocasionando a presença de vetores como moscas, besouros e sapos, contradizendo o que preconiza a Instrução Normativa 51 do Ministério da Agricultura, Pecuária e Abastecimento (BRASIL, 2002), que declara que todo local de ordenha deve ser mantido sob rigorosas condições de higiene. Além disso, a presença de sujidades no local estabelece condições favoráveis ao desenvolvimento microbiano.

O banheiro usado pelos funcionários possui vaso sanitário com tampa, lavatório, chuveiro e armário metálico. Entretanto, não foram encontrados produtos de limpeza pessoal (sabonete ou detergente), tampouco um sistema de secagem para as mãos (ar quente ou toalhas de papel). Com isso, o banheiro não está totalmente de acordo com as exigências da IN 51, visto que, pela legislação vigente, os lavatórios devem dispor, permanentemente, de sabão líquido e neutro, toalhas descartáveis e cestas coletoras.

Riscos de acidente (ou mecânico)

Dentre os EPI's (Equipamentos de Proteção Individual), o único observado foi o uso das botas 
antiderrapantes. A vestimenta utilizada pelos funcionários pode-se resumir basicamente a: boné, camisa, calça, bota e avental (sendo esse último usado esporadicamente). Tendo em vista as questões de segurança do trabalho, somadas às BPF (Boas Práticas de Fabricação), as vestimentas apresentadas são insuficientes para o manuseio de alimentos. De acordo com a IN 51 (BRASIL, 2002), todos os funcionários ocupados com operações nas dependências de ordenha devem usar uniformes brancos completos (gorro, macacão ou jaleco, calça e botas). Para os demais, devem ser uniformes azuis e botas pretas. O descumprimento de tal normativa pode estar associado ao fato de os operadores de ordenha desempenharem outras funções fora da granja leiteira. Entretanto, a mesma normativa descreve que a divisão dos trabalhos deve ser feita de maneira que o ordenhador se restrinja a sua função, cabendo aos outros trabalhadores as demais operações.

O trabalho com animais de grande porte foi considerado um risco de acidente, visto que, se estes animais estiverem em situação de estresse ou se houver falha no manejo, o funcionário pode estar em risco. Por isso, a Norma Regulamentadora 31 indica que, em todas as etapas dos processos de trabalhos com animais, devem ser disponibilizadas aos trabalhadores informações sobre formas corretas e locais adequados de aproximação, contato e imobilização (BRASIL, 2005).

Outros riscos de acidente encontrados foram o piso molhado, aliado a irregularidades na escada que dá acesso a sala de ordenha. O primeiro ocorre porque, durante o processo, o funcionário faz a lavagem dos tetos, como descrito anteriormente, resultando em acúmulo de água no fosso, contribuindo para o risco de escorregões e/ou quedas. Já as irregularidades na escada são: a falta de algumas peças cerâmicas e a ausência do corrimão. A Norma Regulamentadora 31 estabelece que, nas escadas, rampas, corredores e outras áreas destinadas à circulação de trabalhadores e à movimentação de materiais, que ofereçam risco de escorregamento, devem ser empregados materiais ou processos antiderrapantes e dispor de proteção contra o risco de queda, logo, as observações supracitadas contrastam com o preconizado na legislação vigente (BRASIL, 2005).

Em seguida a apresentação e análise dos resultados, algumas sugestões são oferecidas para a resolução dos problemas a curto, médio e longo prazo, cuja maioria representa medidas simples e de pequeno investimento. Primeiramente, o local de ordenha deve dispor de bancos para que os funcionários possam, quando possível, alternar as atividades entre as posições em pé e sentado. Ou, de acordo com a orientação do subitem 17.3.5., da Norma Regulamentadora 17, devem ser colocados assentos para descanso em locais em que possam ser utilizados por todos os trabalhadores durante as pausas.
Quanto às precauções com relação à higienização e riscos de acidentes, tem-se a aquisição de uniformes brancos completos (gorro, macacão ou jaleco, calça e botas) para todos os funcionários ocupados com operações nas dependências de ordenha e uniformes azuis e botas pretas para os demais funcionários, conforme a IN 51. O banheiro deve dispor de produtos de limpeza pessoal (sabonete ou detergente) e de um sistema de secagem para as mãos (ar quente ou toalhas de papel). Complementarmente, ações que visem a uma melhor drenagem da água na sala de ordenha devem ser tomadas, como, por exemplo, a reposição de algumas peças cerâmicas e instalação de um corrimão na escada, mitigando assim o risco iminente de acidente devido às quedas e escorregões.

Por fim, sugere-se que seja feito com os funcionários um treinamento de conscientização e capacitação em saúde e segurança no trabalho, o que irá orientá-los sobre como exercer suas funções de maneira que preservem sua saúde, formando, assim, pessoas mais conscientes e criando um ambiente de trabalho mais seguro e saudável, conforme o recomendando na Norma Regulamentadora 31 (BRASIL, 2005). A partir da implantação da ação anterior, recomenda-se outro levantamento de riscos ocupacionais, o qual deverá envolver todos os trabalhadores capacitados. Esta ação visa à integração dos trabalhadores e ainda a comparação com os resultados apresentados neste trabalho.

\section{CONCLUSÃO}

Os resultados obtidos mostram a necessidade de mudanças no setor de ordenha, de forma a melhorar a relação homem x trabalho. Tais alterações, possivelmente, colaborarão para a redução dos riscos ocupacionais identificados. Isso reforça a ideia de que os ambientes de trabalho devem ser projetados pensando não só nas características técnicas relativas à construção, mas também na atividade a ser realizada, no tempo de permanência no posto de trabalho e, principalmente, nas características do trabalhador. Esses fatores, uma vez considerados, poderão contribuir para a garantia da segurança e a saúde do trabalhador, com efeitos na maximização da qualidade e produtividade dos serviços por ele realizados (RODRIGUES et al., 2008).

Com um diagnóstico embasado em observações sistemáticas e entrevistas informais, evidenciou-se como principal risco encontrado o ergonômico. Logo, apresenta-se como necessidade a avaliação dos riscos biomecânicos, com o intuito de estudar os movimentos corporais e as forças relacionadas ao trabalho, por serem pontos fundamentais das interações físicas do trabalhador, com o seu posto de trabalho, ferramentas e materiais. 
Ante aos resultados apresentados, tornouse perceptível que tão importante quanto a segurança do produto, deveria ser a qualidade das condições dos ambientes de trabalho em que estes são produzidos, tendo em vista que o trabalhador é (e deve ser sempre considerado) o principal ator desse processo. Para isso, destaca-se que qualquer investimento com segurança reflete positivamente na qualidade de vida do trabalhador e, consequentemente, na sua capacidade produtiva, além de evitar possíveis gastos com indenizações e demais transtornos ao empregador.

\section{AGRADECIMENTOS}

À Fundação de Amparo à Pesquisa do Estado da Bahia (FAPESB), pela bolsa de Iniciação Científica concedida ao primeiro autor, Leonardo Rocha Maia.

\section{REFERÊNCIAS}

ALEXANDRE, N.M.C. Ergonomia e as atividades ocupacionais da equipe de enfermagem. Revista da Escola de Enfermagem - USP, São Paulo, v.32, n.1, p.84-90, 1998. Disponível em: $<$ http://www.scielo.br/scielo.php?script=sci_arttext\&pid=S0080$62341998000100013 \& \operatorname{lng}=p t \& n r m=i s o>$. Acesso em: $10 \mathrm{fev}$. 2010. doi: 10.1590/S0080-62341998000100013.

BEZERRA, E. et al. Análise ergonômica da atividade dos trabalhadores do setor de expedição de uma industria alimentícia. In: ENEGEP - ENCONTRO NACIONAL DE ENGENHARIA DE PRODUÇÃO, 18., 1998, Niterói, RJ. Anais... Rio de Janeiro, RJ: Associação Brasileira de Engenharia de Produção, 1998. 8p.

BRASIL. Lei no 5.889 de 08 de junho de 1973. Brasília, DF, 1973. Disponível em: <http://www.planalto.gov.br/ccivil_03/ leis/L5889.htm>. Acesso em: 10 fev. 2010.

BRASIL. Ministério do Trabalho e Emprego. Portaria no 3.067 de 12 de abril de 1988. Brasília, DF, 1988. Disponível em: <http://www.mte.gov.br>. Acesso em: 10 fev. 2010.

BRASIL. Ministério da Agricultura Pecuária e Abastecimento. Instrução Normativa no $\mathbf{5 1}$, de 18 de setembro de 2002 . Brasília, DF, 2002. Disponível em: <http://www.agricultura.gov.br>. Acesso em: 10 fev. 2010.

BRASIL. Ministério do Trabalho e Emprego. Norma Regulamentadora 17 - Ergonomia. Portaria SIT no 13, de 21 de junho de 2007. Brasília, DF, 2007. Disponível em: <http:/ /www.mte.gov.br>. Acesso em: 10 fev. 2010.

BRASIL. Ministério do Trabalho e Emprego. Norma Regulamentadora 31 - Segurança e saúde no trabalho na agricultura, pecuária silvicultura, exploração florestal e aqüicultura. Portaria GM no 86, de 03 de março de 2005. Brasília, DF, 2005. Disponível em: <http://www.mte.gov.br>. Acesso em: 10 fev. 2010

DUL, J.; WEERDMEESTER, B. Ergonomia prática. São Paulo: Edgard Blücher, 2004. 137p.

FAESP (Federação da Agricultura e Pecuária do Estado de São Paulo). Bovinos de leite. Disponível em: < http:// www.faespsenar.com.br/faesp/pagina/exibe/faesp/produtos/ bovinos-de-leite/697>. Acesso em: 10 fev. 2010.
FEHLBERG, M.F. et al. Prevalência e fatores associados a acidentes de trabalho em zona rural. Revista de Saúde Pública, São Paulo, v.35, n.3, p.269-275, 2001. Disponível em: <http:/ /www.scielo.br/scielo.php?script=sci_arttext \&pid=S003489102001000300009\&lng=pt\&nrm=iso $>$. Acesso em: $10 \mathrm{fev}$. 2010. doi: 10.1590/S0034-89102001000300009.

GALVÃO, L. Histórico da segurança no trabalho rural. Disponível em: <http://www.riscorural.com.br/riscos-no-trabalhorural/23-historico-seguranca-no-trabalho-rural>. Acesso em: 10 fev. 2010.

IBGE (Instituto Brasileiro de Geografia e Estatística). Estatística da produção pecuária - Terceiro trimestre de 2010. Disponível em: <http://www.ibge.gov.br/home/estatistica/ indicadores/agropecuaria/producaoagropecuaria/abate-leite-couroovos_201003comentarios.pdf>. Acesso em: 10 fev. 2010.

IIDA, I. Ergonomia - Projeto e produção. São Paulo: Edgard Blücher, 2005. 630p.

MATTOS, P.L.C.L. A entrevista não-estruturada como forma de conversação: razões e sugestões para sua análise. Revista de Administração Pública, Rio de Janeiro, v.4, n.39, p.823-847, 2005.

NEUENFELD, D.R. et al. Sistema de gestão ambiental em um empreendimento de suinocultura. In: SEMEAD - SEMINÁRIOS EM ADMINISTRAÇÃO FEA - USP, 9., 2006, São Paulo, SP. Anais... São Paulo, SP: Programa de Pós-graduação em Administração da FEA/USP, 2006. 15p. Disponível em: <http:/ /www.ead.fea.usp.br/semead/9semead/resultado_semead/ trabalhosPDF/274.pdf>. Acesso em: 10 fev. 2010.

REINEMANN, D.J. A review of studies on the ergonomics of milking. Madison: University of Wisconsin Milking and research and Instruction Lab Wisconsin, 2005. 2p.

RODRIGUES, L.B.; SANTANA, N.B. Identificação de riscos ocupacionais em uma indústria de sorvetes. UNOPAR Científica. Ciências Biológicas e da Saúde, Paraná, v.12, p.1-18, 2010.

RODRIGUES, L.B. et al. Apreciação ergonômica do processo de produção de queijos em indústrias de laticínios. Revista Produção Online, Santa Catarina, v.8, p.1-18, 2008.

SALIBA, T.F. Curso básico de segurança e higiene ocupacional. 2.ed. São Paulo: LTr, 2008. 456p.

SILVA, R.B.T.R. et al. Insalubridade do trabalhador na produção animal: uma questão de educação e informação. Disponível em: <www.segurancaetrabalho.com.br/download/prodanimal.pdf $>$. Acesso em: 10 fev. 2010.

SOARES, M.S. O engenheiro agrônomo e a NR 31. Passo Fundo: Conselho em Revista no 39. Área técnica - Artigos, 2007. 26p.

VILELA, D. A importância econômica, social e nutricional do leite. Revista Batavo, Castro, PR, n.111, dezembro 2001/ janeiro, 2002. Disponível em: <http://www.nupel.uem.br>. Acesso em: 10 fev. 2010.

ZOCCHIO, A. Prática da prevenção de acidentes: ABC da segurança do trabalho. 7.ed. rev. e ampl. São Paulo: Atlas, 2002. 280p. 